\title{
'PROJECTA PARAPLEGICA'
}

\author{
By L. S. Michaelis, M.D. \\ Aylesbury, England
}

I would like to discuss a method designed to help overcome the difficulties that have to be faced when someone has an idea for research-either clinical or laboratory-but has not sufficient facilities to carry out this research.

I believe that cooperation between centres-especially the newer and smallerwhen planning research would help solve any problems involved such as lack of apparatus or clinical cases, even in old established and large centres. Some years ago, I illustrated this by circularising some 40 centres in 16 countries in an attempt to get agreement on neurological nomenclature and certain facets of spinal neurology. This was followed by the Heidelberg inquiry into childbirth and children of paraplegic mothers; this inquiry being based, in part, on the results of other centres.

It is my belief that collaboration between members of different centres should be further extended, in suitable cases, before there is anything on paper. So, whatever question is asked it can be answered on a wider basis and with the aid of more sophisticated laboratory techniques than are available to the originator of the idea.

\section{TABLE}

Projecta Paraplegica

\begin{tabular}{|c|c|l|}
\hline Name & Address & \multicolumn{1}{c|}{ Project and Requirements } \\
\hline $\begin{array}{c}\text { A.B. } \\
\text { C. }\end{array}$ & $\begin{array}{c}\text { X.Y. } \\
\text { Z. }\end{array}$ & $\begin{array}{l}\text { First signs of conus-involvement in C.-E. } \\
\text { lesions. } \\
\text { Need: } \text { further well-documented patients }\end{array}$ \\
\hline $\begin{array}{c}\text { D.E. } \\
\text { F. }\end{array}$ & $\begin{array}{c}\text { P.Q. } \\
\text { R. }\end{array}$ & $\begin{array}{l}\text { Differences in uretero-vesical anatomy of } \\
\text { males and females. } \\
\text { Need: further specimens }\end{array}$ \\
\hline $\begin{array}{c}\text { H.H. } \\
\text { G. }\end{array}$ & $\begin{array}{c}\text { S.T. } \\
\text { U. }\end{array}$ & $\begin{array}{l}\text { 'Futurol': action and side-effects on the } \\
\text { circulation in the injured cord. } \\
\text { Animal experiments. } \\
\text { Need: collaboration in design, method and } \\
\text { measurement. }\end{array}$ \\
\hline
\end{tabular}

If after being discussed fully by the Society 'Projecta Paraplegica' is accepted for publication in this Journal I think it could perhaps follow a format giving details of the prospective author's name; centre; definition of the research project and its 
requirements-collaborators from other centres willing to join him by adding some of their own patients or offering technical facilities. (Table)

Some members of the Society might fear that their 'priority' would be endangered by this, but the fact alone that their name has appeared on the 'projecta page' would be a safeguard. Once the paper has been written the name may be singled out by either bolder type or underlining so in fact giving more prominence.

If this proposal is accepted, the International Medical Society of Paraplegia would, I believe, be a pioneer with a method which might be found useful in 'projecta' published in other disciplines.

The advantages of such a method would be:

I. an improvement in the quality and weight of the papers published by inter-centre teams.

2. a reduction in the quantity of papers based on insufficient material.

3. a saving of scarce money for equipment with expensive apparatus which would serve research beyond the limits of one centre. 